\title{
New role for Agrin in T cells and its potential importance in immune system regulation
}

\author{
Elizabeth C Jury*1 and Panagiotis S Kabouridis ${ }^{* 2}$
}

\begin{abstract}
Agrin plays a crucial role in the maintenance of the neuromuscular junction. However, it is expressed in other tissues as well, including T lymphocytes, where cell activation induces its expression. Agrin from activated $T$ cells has the capacity to induce aggregation of key receptors and to regulate signalling. Interestingly, T cells isolated from patients with systemic lupus erythematosus over-express Agrin and its co-stimulation with the $T$ cell receptor enhances production of pathogenic cytokines. These early studies point to an important function for Agrin in $T$ cell biology and make the case for a more thorough and systematic investigation into its role in the immune system.
\end{abstract}

\section{Introduction}

Immunity against pathogens and cancer requires cell-cell interactions, the type, strength, and duration of which determine to a large extent the final outcome of the immune response. In this process, $\mathrm{T}$ cells transiently interact with specialised antigen presenting cells (APCs) to sample the nature of the prevalent antigens in the body. Recognition of foreign antigen by the $\mathrm{T}$ cell receptor (TCR) results in the strengthening of the T cellAPC interaction, which is primarily mediated by an increase in the affinity of integrins for their corresponding ligand in a process known as 'inside-out signalling' [1]. The resulting stable interaction between a $\mathrm{T}$ cell and its cognate APC is the formation of a synapse between the two cells, generally referred to as the immunological synapse (IS) [2] owing to its similarity to the neuronal synapse [3]. The strength and duration of cell-cell

\footnotetext{
*Correspondence: e.jury@ucl.ac.uk, p.s.kabouridis@qmul.ac.uk

'Centre for Rheumatology, Royal Free and University College Medical School, University College London, London W1P 4JF, UK

2Biochemical Pharmacology, Barts and The London School of Medicine and Dentistry, Queen Mary University of London, Charterhouse Square, London $\mathrm{EC} 1 \mathrm{M} 6 \mathrm{BQ}$, UK
}

interactions play a critical role in the activation of $\mathrm{T}$ cells; thus, a reduced capability to interact might result in failure to generate a good response when needed, whereas increased and/or sustained interaction might result in a breach of tolerance against self antigens, leading to the development of autoimmunity.

The formation of a mature IS has been characterized recently using advances in imaging techniques [4]. Initial activation of the TCR leads to the rapid formation of microclusters that contain phosphorylated-active TCR associated with the proximal signalling proteins Lck, ZAP-70 and LAT [5,6]. These microclusters are active signalling structures involving the actin cytoskeleton, since inhibition of actin polymerization prevents their formation [7]. The TCR microclusters coalesce to form the central region of the IS - known as the central supramolecular activation cluster (cSMAC) - which also contains important coreceptors, such as CD4 and CD28, and key signalling proteins, such as PKCO [7-9]. Receptors accommodated in the cSMAC are of small molecular mass, while large and heavily glycosylated proteins, such as LFA-1 (lymphocyte function-associated antigen 1), $\mathrm{CD} 43$, and the tyrosine phosphatase CD45, accumulate in a ring around the central region called the peripheral supramolecular activation cluster (pSMAC) $[10,11]$. The mature IS with its defined areas is thought to control various cell-cell interaction-mediated processes by influencing signal transduction, leading to differential cell functions, and also signal termination and dissolution of cell conjugates [12,13].

Interestingly, recent studies have shown that certain proteins with an established function in the neuronal synapse are also expressed by different $\mathrm{T}$ cell subsets. For example, regulatory $\mathrm{T}$ cells (Tregs), which are shown to be better poised to interact with APCs compared to naïve $\mathrm{T}$ helper (Th) cells, express neuropilin-1 [14]. This molecule enhanced Treg interaction with APCs and its down-regulation by means of small interfering RNA resulted in a concomitant reduction in the ability of Tregs to form long-lasting synapses. Neuropilin-1 was not detected in naïve Th cells and this lack of expression correlated with their reduced capacity to form stable synapses. Interestingly, ectopic expression of neuropilin-1 

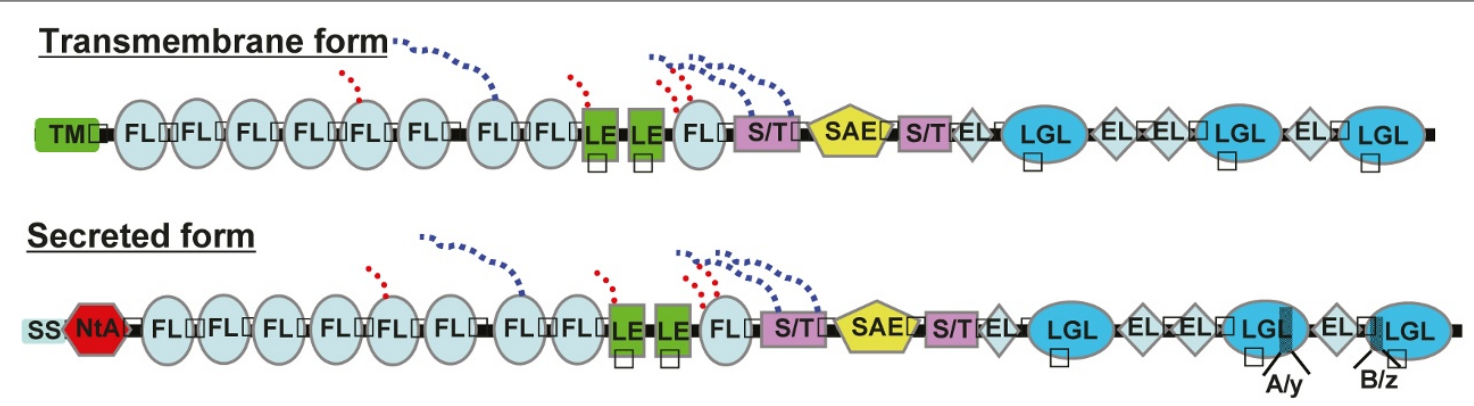

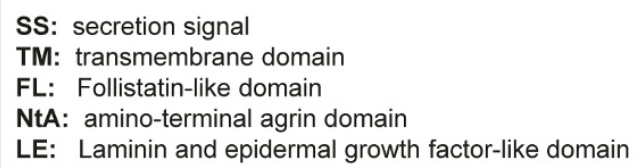

TM: transmembrane domain

FL: Follistatin-like domain

NtA: amino-terminal agrin domain

LE: Laminin and epidermal growth factor-like domain

S/T: Serine/Threonine rich domain

SAE: sperm protein, enterokinase and agrin domain

EL: epidermal growth factor-like domain

LGL: Laminin G-like domain

$A / y$ and $B / z$ : sites of alternative splicing

Red and blue dots: glycosylation sites

Figure 1. Depiction of the secreted and transmembrane forms of the Agrin protein. Various structural domains of the protein are indicated by differential colouring.

resulted in a higher number of long-lasting interactions between Th cells and APCs [14]. CRMP2 (Collapsin response mediator protein 2) is another neural protein found to be expressed in $\mathrm{T}$ cells and to have a role in their polarization and migration [15]. Down-regulation of CRMP2 expression dampened the chemokine-induced transmigratory ability of human T cells. Significantly, CRMP2 was over-expressed in $\mathrm{T}$ cells from patients with neuroinflammatory disease, which were found to have elevated transmigratory activity [15]. Relevant to this intense area of research is the recent association of the molecule Agrin with the formation of the T cell-APC IS.

\section{The Agrin protein}

Agrin was initially isolated from basal lamina extracts of Torpedo californica (electric ray) and shown to have the ability to induce differentiation of the postsynaptic membrane of muscle cells [16]. Cloning of the gene and follow-on studies have shown that it is produced by motor neurons at the neuromuscular junction (NMJ), where it induces aggregation of acetylcholine receptors on the membrane of myotubes by activating the musclespecific kinase (MuSK) [17]. Agrin is a heparan sulphate proteoglycan (HSPG) with a large core protein backbone that includes a number of distinct structural domains (Figure 1). There are extensive $\mathrm{O}$ - and N-linked glycosylations at the amino-terminal half of the protein with the addition of heparan sulphate glycosaminoglycan at the O-linked carbohydrate moieties (reviewed in [18]). The transcript of the Agrin gene can be differentially spliced to produce different isoforms of the protein, which determine its localization and function. Alternative splicing at the amino terminus produces either a type II transmembrane protein (TM-Agrin) or a secreted protein (SS-Agrin) [19,20] (Figure 1). SS-Agrin also contains a laminin-binding domain immediately following the secretion sequence, which anchors the secreted form to the extracellular matrix $[19,20]$. There are at least two additional splicing sites close to the carboxyl terminus of the protein know as $\mathrm{A} / \mathrm{y}$ and $\mathrm{B} / \mathrm{z}$ (A and $\mathrm{B}$, and $\mathrm{y}$ and $\mathrm{z}$ specify the sites in the chick and mammalian proteins, respectively; Figure 1). Alternative splicing at these sites produces Agrin isoforms that contain or lack inserts at the $A / y$ and $B / z$ sites [18]. The importance of splicing at the $\mathrm{B} / \mathrm{z}$ site is well documented; inclusion of inserts $(\mathrm{B} / \mathrm{z}+$ forms) increases the activity of Agrin at the NMJ by many fold [21]. Motor neurons produce SS-B/z+ Agrin, which is crucial for the stabilization and functionality of the NMJ. The Agrin form expressed in other tissues, including $\mathrm{T}$ lymphocytes, is the $\mathrm{B} / \mathrm{z}$ - form. Our knowledge on the function of $\mathrm{B} / \mathrm{z}-$ Agrin in these tissues remains limited at present.

Agrin is highly expressed in the brain, where its function has been linked to proper synaptic transmission of excitatory but not inhibitory synapses in the cerebral cortex. Mutant mice deficient in Agrin expression have non-functional NMJs and die before or shortly after birth due to asphyxiation [22]. However, perinatal death can be rescued by the specific expression of Agrin in motor neurons [23]. These mice exhibit a reduced number of presynaptic and postsynaptic specializations in the brain, indicating that Agrin has a role, at least in part, in maintaining synaptic structure in this tissue [23]. In addition, Agrin is expressed at high levels in the brain microvasculature, where it could play a role in the maintenance of the blood-brain barrier [24]. Reduction 
of Agrin expression could compromise the integrity of the blood-brain barrier, possibly resulting in uncontrolled immune cell infiltration.

\section{Agrin in T cells and lupus autoimmunity}

Expression of Agrin in T cells has been documented by Northern and Western blotting, and PCR. Initially, Khan and colleagues [25] reported its expression in murine thymocytes and splenocytes, and demonstrated that following $\mathrm{T}$ cell activation Agrin is post-translationally modified; it migrates with increased mobility in polyacrylamide gels. Agrin clustered on the surface of activated T cells, and colocalised with the TCR and associated signalling proteins. Co-stimulation with antiCD3 and anti-Agrin antibodies augmented $\mathrm{T}$ cell proliferation, particularly when low concentrations of the anti-CD3 antibody were used. Furthermore, purified Agrin from activated, but not resting, $\mathrm{T}$ cells when added to the culture medium of non-activated $\mathrm{T}$ cells induced clustering of lipid rafts (lipid rafts are reviewed in [26]) and of the TCR [25]. Interestingly, Agrin from activated $\mathrm{T}$ cells induced clustering of acetylcholine receptors when added to myotube cultures, indicating that certain modifications endow the $\mathrm{B} / \mathrm{z}$ - Agrin with functions characteristic of $\mathrm{B} / \mathrm{z}+$ Agrin [25]. This is an important observation because most tissues express B/z- Agrin. A subsequent publication, using specific anti-sense constructs to down-regulate Agrin expression in lymphocytes, has confirmed its importance in $\mathrm{T}$ cell activation and suggested that $\alpha$-dystroglycan, a known Agrin receptor in other tissues, is also important for Agrin action in T cells [27]. Furthermore, Agrin was localized at the IS during antigen presentation [25,27]. Based on these results, it was proposed that $\mathrm{T}$ cell activation induces an as yet unknown modification of Agrin that endows it with higher aggregating activity, and furthermore redistributes the protein to the site of the IS where it may facilitate antigen presentation (Figure 2).

Microarray analyses of transcripts expressed in blood mononuclear cells from patients with systemic lupus erythematosus revealed a type I interferon response [28-31]. Among the genes found to be upregulated was that encoding Agrin $[28,30]$. We found that both $\mathrm{CD}^{+}$ and $\mathrm{CD} 8^{+} \mathrm{T}$ cell subsets from lupus patients expressed higher levels of Agrin protein compared to healthy controls [32]. Its expression was gradually reduced when the cells were cultured in vitro but was induced upon stimulation with anti-CD3/CD28 antibodies. A similar increase was seen following in vitro treatment of $\mathrm{T}$ cells with INF $\alpha$. Therefore, factors that regulate T cell Agrin expression include TCR and INF $\alpha$ activation [32]. Interestingly, an investigation of the genomic position of Agrin in various genomes available in the databases reveals that in all eutherians (placental mammals), Agrin

\section{Anti-Agrin immunostain}

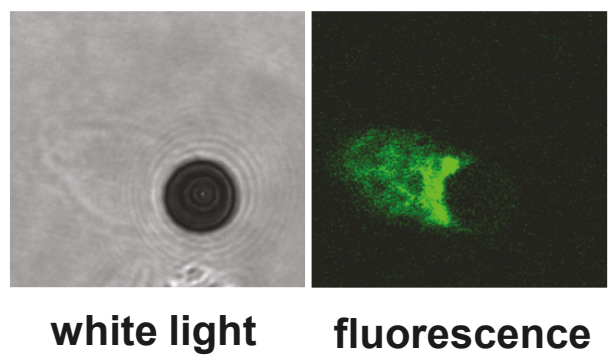

Figure 2. Agrin localization in T cells during their in vitro activation. Confocal picture of a conjugate between a human CD4 ${ }^{+}$ T cell and an anti-CD3/CD28-coated stimulatory bead. Agrin was visualized with the $\mathrm{m} 247$ anti-Agrin antibody.

Table 1. Genomic location of the Agrin gene in genomes available at the National Center for Biotechnology Information

\begin{tabular}{lcc}
\hline Species & ISG15-Agrin linkage & Chromosome \\
\hline Eutheria & Yes & 1 \\
Homo sapiens & Yes & 1 \\
Pan troglodytes & Yes & 1 \\
Macaca mulatta & Yes & 16 \\
Bos Taurus & Yes & 5 \\
Canis lupus familiaris & Yes & 4 \\
Mus musculus & Yes & 5 \\
Rattus norvegicus & & \\
Other & No & $\|$ \\
Caenorabditis elegans & No & 21 \\
Gallus gallus & No & 23 \\
Danio rerio & &
\end{tabular}

is found immediately downstream and in the same transcriptional direction with the ISG-15 (Interferon stimulated gene of $15 \mathrm{kDa}$ ) gene, which is an established type I INF-induced gene (Table 1). The preservation of this genomic arrangement might indicate that type I IFNs control the expression of the Agrin gene; however, at present this is only an assumption and it remains to be seen whether Agrin plays a role in the INF system.

\section{A working hypothesis on the function of Agrin in the immune system}

Although the number of studies investigating the function of Agrin in the immune system is limited at present, based on the above results, a hypothesis can be put forward for future scrutiny. Agrin expression in $T$ cells could be upregulated in the course of a pathogenic infection and, in its activated form, could interact with a 

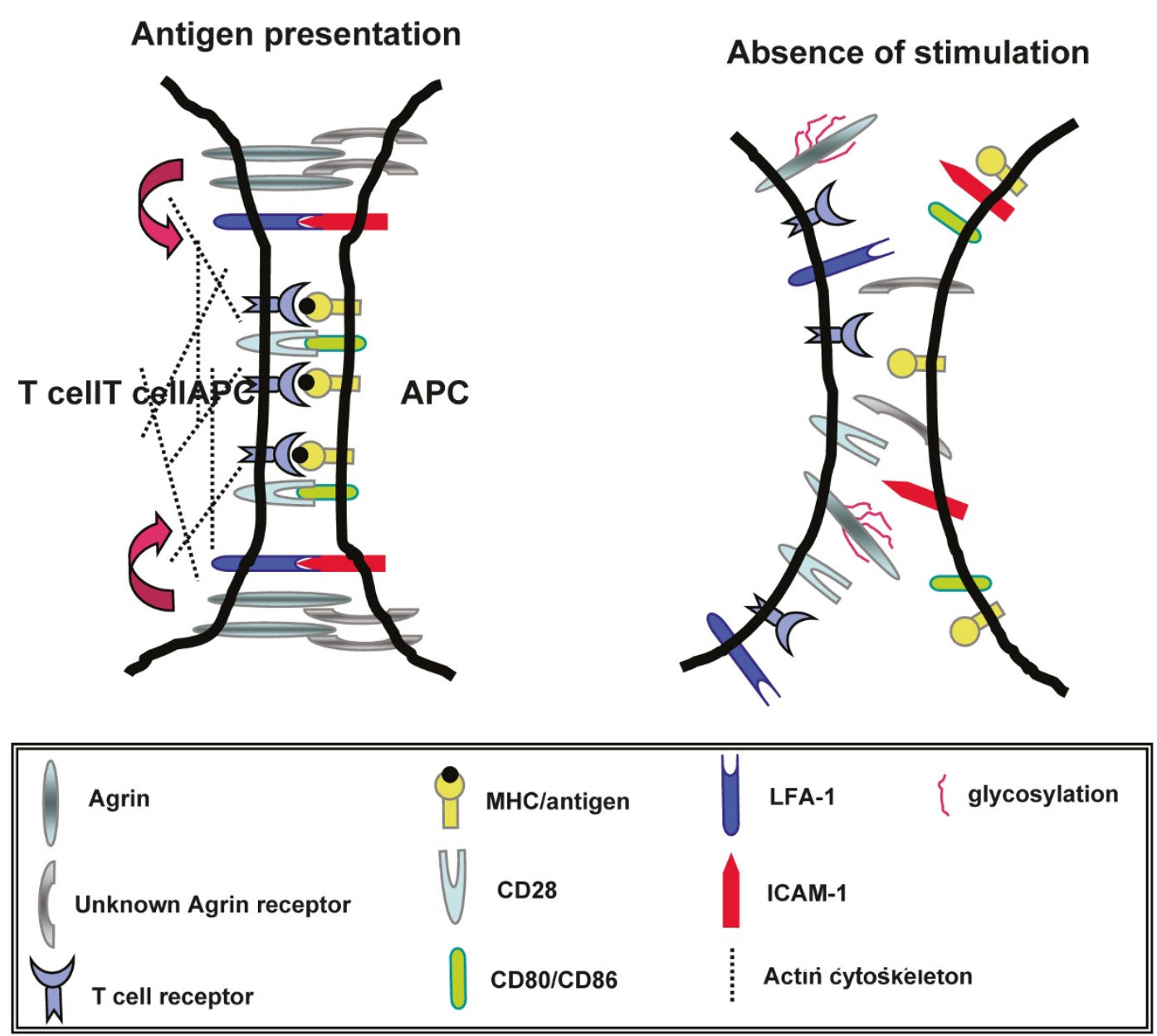

Figure 3. Schematic illustration showing a potential function for Agrin in the context of the immunological synapse. The organization of key surface receptors is illustrated in the context of the mature immunological synapse structure during antigen presentation or in the absence of stimulation. Agrin is shown in its fully glycosylated (no activation) and modified (activation) forms. Also shown is a hypothetical receptor for Agrin expressed by the antigen presenting cell (APC). ICAM, intracellular adhesion molecule; LFA, lymphocyte function-associated antigen; MHC, major histocompatibility complex.

potential counter-receptor on the site of the APC, thus contributing to the enhanced and sustained cell-cell adhesion required for successful $\mathrm{T}$ cell activation (Figure 3). Agrin was found to be a functional receptor on the surface of $\mathrm{T}$ cells since its crosslinking using specific antibodies resulted in activation of the ERK MAPK (mitogen-activated protein kinase) cascade and reorganisation of the actin cytoskeleton [32]. Therefore, signals generated by stimulated Agrin on the cell surface could result in the remodelling of the actin cytoskeleton, facilitating signalling by the engaged TCR (Figure 3). This scenario agrees with recent publications highlighting the importance of the actin cytoskeleton in the spatiotemporal formation of the IS and $\mathrm{T}$ cell activation [33]. Nonetheless, there is still a lot to be learned about the function of Agrin in T cells. Its role during activation of
$\mathrm{T}$ cells in vivo remains untested; such experiments are awaiting the use of appropriate mouse lines and in vivo models. A key observation from the studies discussed above is that elevated Agrin expression and its posttranslational modification is a characteristic of activated $\mathrm{T}$ cells. This is also the case for $\mathrm{T}$ cells isolated from lupus patients. An interesting question arising from this finding is whether higher or modified levels of Agrin are indicative of autoreactive $\mathrm{T}$ cells for certain types of autoimmunity. Monitoring levels of Agrin expression in $\mathrm{T}$ cells by sampling a cohort of lupus patients with active and inactive disease in a longitudinal study should provide interesting results, and development of reagents such as monoclonal antibodies that are selective for modified Agrin might prove useful as tools to monitor disease severity or progression. 


\section{Other reported functions of Agrin}

Its widespread expression suggests that Agrin is important in other tissues. It has been reported that Agrin is required for efficient transcytosis of HIV-1 across epithelial cell monolayers by means of formation of the so-called 'virological synapse' [34]. This structure, formed between HIV-infected cells and healthy mucosal epithelial surface, supports a more efficient viral transcytosis compared to cell-free virus. Agrin expressed on mucosal epithelial cells bound to the envelope glycoprotein gp41, and this interaction substantially enhanced HIV-1 trancytosis [34]. Importantly, an antiAgrin antibody reduced virus transcytosis in vitro, suggesting that blocking Agrin on the surface of epithelial cells early on during infection could limit the initial viral load.

Agrin-null mice can be rendered viable by the restricted ectopic expression of Agrin specifically in motor neurons [35]. A study of these mice revealed reduced growth and impaired skeletal development. Examination of long bones showed changes in the morphology and matrix composition of the growth plate, most notably in the thickness of the hypertrophic chondrocyte zone, which was reduced by up to $50 \%$ [35]. Analysis of wild-type mice revealed high expression of Agrin in chondrocytes. These findings might point to an important role for Agrin in chondrocyte biology, the details of which, however, remain unexplored at present.

Agrin was found to be a major HSPG expressed in the glomerular basement membrane (GBM) of kidneys [36-38]. It was initially proposed that the high anionic content of HSPGs in GBM is a critical factor controlling glomerular permeability, and the observed reduction of heparan sulphate levels in various renal inflammatory diseases, including lupus nephritis, was associated with the increased GBM permeability seen in these diseases $[39,40]$. However, recent studies have directly investigated the contribution of Agrin to GBM functionality by using mutant mice deficient for Agrin expression specifically in podocytes [41-43]. These mice, despite the strong reduction in the anionic content of the GBM, did not display any changes in glomerular architecture and had normal renal function, suggesting that Agrin is not required for establishment or maintenance of GBM architecture [41]. Therefore, the role of Agrin in this tissue remains unresolved.

\section{Potential Agrin receptors in the immune system}

Agrin is a large HSPG containing many distinct structural domains (Figure 1), and to date several Agrin binding partners have been identified, including: fibroblast growth factor 2, which binds to Agrin heparan sulphate moieties [44]; $\alpha$-dystroglycan and laminins [45-47], which are components of the extracellular matrix; adhesion molecules, such as neural cell adhesion molecule [48]; and integrins that contain the $\beta 1$ subunit [49]. Furthermore, the $\alpha 3$ subunit of the $\mathrm{Na}+\mathrm{K}+$ ATPase $(\alpha 3 \mathrm{NKA})$ was found to serve as an Agrin receptor in neurons of the central nervous system [50]. Agrin binding to cortical neurons inhibited $\alpha 3$ NKA activity, resulting in membrane depolarization and increased action potential frequency [50]. Also, $\alpha 3$ NKA was found to mediate, at least in part, the effects of Agrin on cardiac myocyte contraction [51].

Recently, two papers have reported the long sought Agrin receptor expressed by the postsynaptic membrane at the NMJ. This was found to be Lrp4 (low-density lipoprotein related protein 4), a member of the lowdensity lipoprotein receptors [52,53]. Lrp4, upon Agrin binding, forms a complex with MuSK, which initiates intracellular signalling leading to the aggregation of acetylcholine receptors. Lrp4 binds to the $\mathrm{B} / \mathrm{z}+$ form of Agrin with an affinity that is many fold higher compared to $\mathrm{B} / \mathrm{z}$ - forms, confirming the selectivity of this receptor for the function of Agrin at the NMJ [52,53]. It is conceivable that outside the NMJ, Agrin mediates its effects through additional receptors that have not been identified yet. One report, discussed above, implicates $\alpha$ dystroglycan as an Agrin receptor in $T$ cells [27]. Nevertheless, a systematic analysis and identification of the types of Agrin receptors expressed will be an essential step in order to understand the biological function of Agrin in the immune system.

\section{Conclusion}

Although Agrin was initially identified as a factor critical for the function of the NMJ, its expression in other tissues, including $\mathrm{T}$ cells, implies a more widespread role. Results from studies in $\mathrm{T}$ cells suggest that Agrin function is linked to TCR signalling and cell activation. Despite these initial findings, there are big gaps in our knowledge regarding the function of Agrin in T cells and the immune system in general, at both the molecular level and at the level of the whole organism. At the molecular level important areas of investigation, although by no means the only ones, are: to understand the nature of Agrin modification induced early on during $\mathrm{T}$ cell activation, which increases its aggregating activity; to explore the role of Agrin in cell-cell adhesion during antigen presentation; and to identify the receptor(s) that mediate the effects of Agrin in immune cells. At the organism level, vital information will be generated by: studying how $\mathrm{T}$ cells and the immune system in general develop in the absence of Agrin expression; assessing changes in immune responses of viable Agrin-/- mice compared to wild type; and studying whether higher expression of Agrin in $\mathrm{T}$ cells in engineered mice predisposes to $\mathrm{T}$ cell hyperactivity and autoimmunity. 
Many tools are already available to study the biology of Agrin and we anticipate that these issues will be addressed in the near future by immunologists with different areas of expertise. These studies may well prove that Agrin has a critical role in the immune system as it has in the NMJ.

\section{Abbreviations}

a3NKA, a3 subunit of the $\mathrm{Na}+/ \mathrm{K}+$ ATPase; APC, antigen presenting cell; CRMP2, collapsin response mediator protein 2; CSMAC, central supramolecular activation cluster; GMB, glomerular basement membrane; HSPG, heparan sulphate proteoglycan; INF, interferon; IS, immunological synapse; Lrp4, low density lipoprotein related protein 4; MuSK, muscle-specific kinase; NMJ, neuromuscular junction; SS, secreted sequence; TCR, T cell receptor; Th, T helper cell; Treg, T regulatory cell.

\section{Competing interests}

The authors declare that they have no competing interests.

\section{Acknowledgements}

This work is supported by an arc Career Development (18106) and a University College London Hospital (CRDC) project grant (GCT/2008/EJ) award to ECJ and an arc project grant (16018) to PSK.

\section{Published: 12 April 2010}

\section{References}

1. Huppa JB, Davis MM: T-cell-antigen recognition and the immunological synapse. Nat Rev Immunol 2003, 3:973-983.

2. Bromley SK, Burack WR, Johnson KG, Somersalo K, Sims TN, Sumen C, Davis MM, Shaw AS, Allen PM, Dustin ML: The immunological synapse. Annu Rev Immunol 2001, 19:375-396

3. Shaw AS, Allen PM: Kissing cousins: immunological and neurological synapses. Nat Immunol 2001, 2:575-576.

4. Kaizuka Y, Douglass AD, Varma R, Dustin ML, Vale RD: Mechanisms for segregating $T$ cell receptor and adhesion molecules during immunological synapse formation in Jurkat T cells. Proc Natl Acad Sci U S A 2007, 104:20296-20301.

5. Yokosuka T, Sakata-Sogawa K, Kobayashi W, Hiroshima M, Hashimoto-Tane A, Tokunaga M, Dustin ML, Saito T: Newly generated T cell receptor microclusters initiate and sustain T cell activation by recruitment of Zap70 and SLP-76. Nat Immuno/ 2005, 6:1253-1262.

6. Varma R, Campi G, Yokosuka T, Saito T, Dustin ML: T cell receptor-proximal signals are sustained in peripheral microclusters and terminated in the central supramolecular activation cluster. Immunity 2006, 25:117-127.

7. Campi G, Varma R, Dustin ML: Actin and agonist MHC-peptide complexdependent $\mathrm{T}$ cell receptor microclusters as scaffolds for signaling. J Exp Med 2005, 202:1031-1036.

8. Depoil D, Zaru R, Guiraud M, Chauveau A, Harriague J, Bismuth G, Utzny C, Muller S, Valitutti S: Immunological synapses are versatile structures enabling selective T cell polarization. Immunity 2005, 22:185-194.

9. Monks CRF, Freiberg BA, Kupfer H, Sciaky N, Kupfer A: Three-dimensional segregation of supramolecular activation clusters in T cells. Nature 1998, 395:82-86.

10. Davis SJ, van der Merwe PA: The kinetic-segregation model: TCR triggering and beyond. Nat Immunol 2006, 7:803-809.

11. Dustin ML: The cellular context of T cell signaling. Immunity 2009 , 30:482-492.

12. Lee KH, Dinner AR, Tu C, Campi G, Raychaudhuri S, Varma R, Sims TN, Burack WR, Wu H, Wang J, Kanagawa O, Markiewicz M, Allen PM, Dustin ML, Chakraborty AK, Shaw AS: The immunological synapse balances T cell receptor signaling and degradation. Science 2003, 302:1218-1222.

13. Saito T, Yokosuka T: Immunological synapse and microclusters: the site for recognition and activation of T cells. Curr Opin Immunol 2006, 18:305-313.

14. Sarris M, Andersen KG, Randow F, Mayr L, Betz AG: Neuropilin-1 expression on regulatory T cells enhances their interactions with dendritic cells during antigen recognition. Immunity 2008, 28:402-413.

15. Vincent $P$, Collette $Y$, Marignier $R$, Vuaillat $C$, Rogemond V, Davoust $N$, Malcus C, Cavagna S, Gessain A, Machuca-Gayet I, Belin MF, Quach T, Giraudon P.
A role for the neuronal protein collapsin response mediator protein 2 in T lymphocyte polarization and migration. J Immuno/ 2005, 175:7650-7660.

16. Nitkin RM, Smith MA, Magill C, Fallon JR, Yao YM, Wallace BG, McMahan UJ: Identification of agrin, a synaptic organizing protein from Torpedo electric organ. J Cell Biol 1987, 105:2471-2478.

17. Ruegg MA, Bixby JL: Agrin orchestrates synaptic differentiation at the vertebrate neuromuscular junction. Trends Neurosci 1998, 21:22-27.

18. Bezakova G, Ruegg MA: New insights into the roles of agrin. Nat Rev Mol Cell Biol 2003, 4:295-308.

19. Burgess RW, Skarnes WC, Sanes JR: Agrin isoforms with distinct amino termini: differential expression, localization, and function. J Cell Bio/ 2000, 151:41-52.

20. Neumann FR, Bittcher G, Annies M, Schumacher B, Kroger S, Ruegg MA: An alternative amino-terminus expressed in the central nervous system converts agrin to a type II transmembrane protein. Mol Cell Neurosci 2001, 17:208-225.

21. Gesemann M, Denzer AJ, Ruegg MA: Acetylcholine receptor-aggregating activity of agrin isoforms and mapping of the active site. J Cell Biol 1995, 128:625-636.

22. Gautam M, Noakes PG, Moscoso L, Rupp F, Scheller RH, Merlie JP, Sanes JR: Defective neuromuscular synaptogenesis in agrin-deficient mutant mice. Cell 1996, 85:525-535.

23. Ksiazek I, Burkhardt C, Lin S, Seddik R, Maj M, Bezakova G, Jucker M, Arber S, Caroni P, Sanes JR, Bettler B, Ruegg MA: Synapse loss in cortex of agrindeficient mice after genetic rescue of perinatal death. J Neurosci 2007, 27:7183-7195.

24. Barber AJ, Lieth E: Agrin accumulates in the brain microvascular basal lamina during development of the blood-brain barrier. Dev Dyn 1997, 208:62-74

25. Khan AA, Bose C, Yam LS, Soloski MJ, Rupp F: Physiological regulation of the immunological synapse by agrin. Science 2001, 292:1681-1686.

26. Jury EC, Flores-Borja F, Kabouridis PS: Lipid rafts in T cell signalling and disease. Semin Cell Dev Biol 2007, 18:608-615.

27. Zhang J, Wang Y, Chu Y, Su L, Gong Y, Zhang R, Xiong S: Agrin is involved in lymphocytes activation that is mediated by alpha-dystroglycan. FASEB $J$ 2006, 20:50-58

28. Baechler EC, Batliwalla FM, Karypis G, Gaffney PM, Ortmann WA, Espe KJ, Shark KB, Grande WJ, Hughes KM, Kapur V, Gregersen PK, Behrens TW: Interferon-inducible gene expression signature in peripheral blood cells of patients with severe lupus. Proc Natl Acad SciU S A 2003, 100:2610-2615.

29. Banchereau J, Pascual V: Type I interferon in systemic lupus erythematosus and other autoimmune diseases. Immunity 2006, 25:383-392.

30. Bennett L, Palucka AK, Arce E, Cantrell V, Borvak J, Banchereau J, Pascual V: Interferon and granulopoiesis signatures in systemic lupus erythematosus blood. J Exp Med 2003, 197:711-723.

31. Pascual V, Farkas L, Banchereau J: Systemic lupus erythematosus: all roads lead to type I interferons. Curr Opin Immunol 2006, 29:29.

32. Jury EC, Eldridge J, Isenberg DA, Kabouridis PS: Agrin signalling contributes to cell activation and is overexpressed in T lymphocytes from lupus patients. J Immunol 2007, 179:7975-7983.

33. Dustin ML Cooper JA: The immunological synapse and the actin cytoskeleton: molecular hardware for T cell signaling. Nat Immunol 2000 1:23-29.

34. Alfsen A, Yu H, Magerus-Chatinet A, Schmitt A, Bomsel M: HIV-1-infected blood mononuclear cells form an integrin- and agrin-dependent viral synapse to induce efficient HIV-1 transcytosis across epithelial cell monolayer. Mol Biol Cell 2005, 16:4267-4279.

35. Hausser HJ, Ruegg MA, Brenner RE, Ksiazek I: Agrin is highly expressed by chondrocytes and is required for normal growth. Histochem Cell Biol 2007, 127:363-374

36. Groffen AJ, Ruegg MA, Dijkman $H$, van de Velden TJ, Buskens $C A$, van den Born J, Assmann KJ, Monnens LA, Veerkamp JH, van den Heuvel LP: Agrin is a major heparan sulfate proteoglycan in the human glomerular basement membrane. J Histochem Cytochem 1998, 46:19-27.

37. Raats CJ, Bakker MA, Hoch W, Tamboer WP, Groffen AJ, van den Heuvel LP, Berden $\mathrm{JH}$, van den Born J: Differential expression of agrin in renal basement membranes as revealed by domain-specific antibodies. J Biol Chem 1998, 273:17832-17838

38. Raats CJ, van den Born J, Bakker MA, Oppers-Walgreen B, Pisa BJ, Dijkman HB, Assmann $\mathrm{KJ}$, Berden $\mathrm{JH}$ : Expression of agrin, dystroglycan, and utrophin in normal renal tissue and in experimental glomerulopathies. Am J Pathol 
2000, 156:1749-1765.

39. Rops AL, van der Vlag J, Lensen JF, Wijnhoven $T J$, van den Heuvel LP, van Kuppevelt TH, Berden JH: Heparan sulfate proteoglycans in glomerular inflammation. Kidney Int 2004, 65:768-785.

40. van den Hoven MJ, Rops AL, Bakker MA, Aten J, Rutjes N, Roestenberg P, Goldschmeding R, Zcharia E, Vlodavsky I, van der Vlag J, Berden JH: Increased expression of heparanase in overt diabetic nephropathy. Kidney Int 2006, 70:2100-2108.

41. Goldberg S, Harvey SJ, Cunningham J, Tryggvason K, Miner JH: Glomerular filtration is normal in the absence of both agrin and perlecan-heparan sulfate from the glomerular basement membrane. Nephrol Dial Transplant 2009, 24:2044-2051.

42. Harvey SJ, Jarad G, Cunningham J, Rops AL, van der Vlag J, Berden JH, Moeller MJ, Holzman LB, Burgess RW, Miner JH: Disruption of glomerular basement membrane charge through podocyte-specific mutation of agrin does not alter glomerular permselectivity. Am J Pathol 2007, 171:139-152.

43. Wijnhoven TJ, Lensen JF, Wismans RG, Lamrani M, Monnens LA, Wevers RA, Rops AL, van der Vlag J, Berden JH, van den Heuvel LP, van Kuppevelt TH: In vivo degradation of heparan sulfates in the glomerular basement membrane does not result in proteinuria. J Am Soc Nephrol 2007, 18:823-832

44. Cotman SL, Halfter W, Cole GJ: Identification of extracellular matrix ligands for the heparan sulfate proteoglycan agrin. Exp Cell Res 1999, 249:54-64.

45. Sugiyama J, Bowen DC, Hall ZW: Dystroglycan binds nerve and muscle agrin. Neuron 1994, 13:103-115.

46. Denzer AJ, Brandenberger R, Gesemann M, Chiquet M, Ruegg MA: Agrin binds to the nerve-muscle basal lamina via laminin. J Cell Bio/ 1997,
137:671-683.

47. Sanes JR, Apel ED, Gautam M, Glass D, Grady RM, Martin PT, Nichol MC, Yancopoulos GD: Agrin receptors at the skeletal neuromuscular junction. Ann N Y Acad Sci 1998, 841:1-13.

48. Storms SD, Kim AC, Tran BH, Cole GJ, Murray BA: NCAM-mediated adhesion of transfected cells to agrin. Cell Adhes Commun 1996, 3:497-509.

49. Martin PT, Sanes JR: Integrins mediate adhesion to agrin and modulate agrin signaling. Development 1997, 124:3909-3917.

50. Hilgenberg LG, Su H, Gu H, O'Dowd DK, Smith MA: Alpha3Na+/K+-ATPase is a neuronal receptor for agrin. Cell 2006, 125:359-369.

51. Hilgenberg LG, Pham B, Ortega M, Walid S, Kemmerly T, O'Dowd DK, Smith MA: Agrin regulation of alpha3 sodium-potassium ATPase activity modulates cardiac myocyte contraction. J Biol Chem 2009, 284:16956-16965.

52. Kim N, Stiegler AL, Cameron TO, Hallock PT, Gomez AM, Huang JH, Hubbard SR, Dustin ML, Burden SJ: Lrp4 is a receptor for Agrin and forms a complex with MuSK. Cell 2008, 135:334-342.

53. Zhang B, Luo S, Wang Q, Suzuki T, Xiong WC, Mei L: LRP4 serves as a coreceptor of agrin. Neuron 2008, 60:285-297.

doi:10.1186/ar2957

Cite this article as: Jury EC, Kabouridis PS: New role for Agrin in T cells and its potential importance in immune system regulation. Arthritis Research \& Therapy 2010, 12:205. 